\title{
Museu integral, museu integrado: a especificidade latino-americana da Mesa de Santiago do Chile
}

Integral Museum, Integrated Museum: the Latin American specificity of the Santiago de Chile Event

hitp://dx.doi.org/10.1590/1982-02672020v28e4

\section{LUCIANA CHRISTINA CRUZ E SOUZA}

https://orcid.org/0000-0001-7067-5933

Museu de Astronomia e Ciências Afins / Rio de Janeiro, RJ, Brasil

RESUMO: Muito se menciona sobre a Mesa de Santiago do Chile como um dos eventos internacionais marcantes para os museus e para a Museologia, seja pelo protagonismo latinoamericano, seja pela tônica dos debates ali traçados e seus claros desdobramentos naquilo que se convencionou chamar de "Nova Museologia". Pouco sabemos ou temos acesso à documentação produzida na ocasião, mas as fontes disponibilizadas nos indicam a preocupação sobre temas relacionados ao desenvolvimento econômico e social da região: urbanização, industrialização e migração, entre outros. É nessa seara que se procurou pensar o papel dos museus, considerando questões específicas das realidades de um território (con)formado historicamente numa clivagem moderno-colonial. Nesse sentido, revela-se primordial contextualizar a Mesa de Santiago do Chile numa miríade de acontecimentos e de ideias que nos oferecem uma perspectiva sobre a expressiva dimensão do evento e a potência do "Museu Integral" em contraposição ao termo "Museu Integrado" quando pensados sobre e a partir da América Latina.

PALAVRAS-CHAVE: América-Latina. Museu. Colonialidade. Desenvolvimento.

\begin{abstract}
1. Mestre e doutora pela Universidade Federal do Estado do Rio de Janeiro (Unirio) no Programa de Pós-Graduação em Museologia e Patrimônio (Unirio/Mast). Graduada em História pela Universidade Federal de Minas Gerais (UFMG). Atualmente é pesquisadora doutora PCI do Museu de Astronomia e Ciências Afins (Mast). E-mail: $<$ lucriscsouza@gmail.com>
\end{abstract}


ABSTRACT: Many often the Santiago de Chile Event was mention as one of the most important international events for museums and Museology, both for Latin American protagonism and for the tone of the debates there and their clear developments in what has been called "New Museology". Less we know or have access to the documentation produced at the time, but the available sources presents the concern about issues related to the economic and social "development" of the continent: urbanization, industrialization, migration, among others. It is in this area that we tried to think about the role of museums, considering specific questions of the realities of a territory historically formed in a modern-colonial cleavage. In this sense, it is essential to contextualize the Santiago de Chile Event in a myriad of events and ideas that offer us a perspective on the expressive dimension of the event and the power of the "Integral Museum" as opposed to the term "Integrated Museum" thought by researches from Latin America.

KEYWORDS: Latin America. Museum. Coloniality. Development. 
A Mesa Redonda de Santiago do Chile é considerada um dos principais eventos realizados entre profissionais de museus e da Museologia envolvendo diferentes países da América Latina. Realizada em 1972 na capital chilena, ${ }^{2}$ a Mesa é tratada pela literatura museal como um marco nas discussões a respeito da responsabilidade social do museu, de sua função sobre o território e da interlocução com a comunidade. $\bigcirc$ tema nos parece muito caro, se considerarmos a importância de um evento daquela magnitude no contexto político latino-americano da década de 1970 e os temas tratados durante as conferências. Para discutir a Mesa de Santiago do Chile, aprofundando-se nos debates realizados ao longo do evento, - presente artigo apresenta três planos de leitura: o primeiro aborda as características gerais da mesa e do seu contexto de realização, contemplando uma breve descrição das fontes disponíveis sobre o evento; o segundo plano de leitura, por sua vez, volta-se à interpretação das fontes a respeito do tema do desenvolvimento da América Latina enquanto uma preocupação manifestada pelos participantes com relação à região; e o terceiro, por fim, compreende a reflexão do termo "Museu Integral" sob uma perspectiva decolonial, considerando sua potência política e epistêmica no contexto de sua formulação.

Para a análise do evento, cabe destacar que o presente artigo toma como principal referência um trabalho realizado pelo Instituto Brasileiro de Museus (IBRAM) em parceria com o Programa lbermuseus e com o Movimento Internacional para uma Nova Museologia (MINoM), o Departamento de Bibliotecas, Arquivos e Museus do Chile e a Organização das Nações Unidas para a Educação, a Ciência e a Cultura (Unesco) em 2012, ocasião em que se comemorava o 40 aniversário de realização da Mesa Redonda de Santiago do Chile. Esta referida publicação reúne documentos relacionados ao evento e entrevistas com participantes e apresenta-se, até o presente momento, como a maior coletânea de fontes primárias traduzidas, sendo elas: a programação da mesa, a agenda de horários, informações gerais para participantes, guia de preparação individual, método de trabalho, lista de participantes e expositores, sinopse das mesas de discussão, discursos proferidos, recomendações à Unesco, relatórios dos debates, resoluções, etc. Tal publicação possui cerca de 240 páginas e se inicia no idioma oficial do evento - o espanhol -, mas igualmente oferece a tradução integral dos textos em português (brasileiro), francês e inglês. Cabe destacar que algumas fontes - aparentemente originais - aparecem digitalizadas na publicação, o que nos permite consultar o vocabulário originalmente acionado nas discussões e transcritos pela relatoria do evento no contexto em questão.
2. Importa destacar que na ocasião de realização do evento o Chile vivenciava o governo de Salvador Allende, eleito democraticamente em 1970 pela União Popular (UP) numa espécie de coalizão de esquerda composta pelos partidos Comunista (PC) e Socialista (PS), pelo Partido Social Democrata (PSD), a Ação Popular Independente (API) e o Movimento de Ação Popular Unificado (Mapu) (Aggio, 2008). O golpe de Estado no Chile ocorreu pouco mais de um ano após a realização da Mesa, sendo marcado pela morte de Salvador Allende durante o bombardeio do Palácio de La Moneda pelas Forças Armadas chilenas. O país passou então a ser governado pelo general $\mathrm{Au}$ gusto Pinochet durante os 17 anos que se seguiram sob apoio estadunidense, protagonizando incontáveis denúncias de mortes, desaparecimentos, exílios e torturas de opositores políticos. 
3. Não se trata de questionar ou reivindicar a origem da expressão "Museu Integral", mas de registrar a singularidade semântica de sua evocação no contexto da Mesa Redonda de Santiago do Chile a partir de debates latino-americanos.

4. O termo faz referência a uma discussão profícua a respeito da ideia de semióforo trabalhada pelo filósofo polonês Krzysztof Pomian (1984). O autor reflete sobre a potência de musealização de qualquer objeto e desenvolve uma reflexão acerca da formação de coleções ligadas a diferentes práticas culturais ao longo da história. Numa perspectiva histórica ocidental, Pomian discorre sobre a correlação de forças sociais que designam a tais artefatos a função de intermediários entre o sagrado e o profano, entre o mundo dos vivos e o mundo dos mortos, ou mesmo entre diferentes segmentos da sociedade, revestindo-os de cuidados específicos que os distanciam das funções originais restringindo-os à admiração em contextos específicos.

5. Fazendo referência a Souza (2018a), importa destacar que os países enquadrados no que se entende como "Norte global" são aqueles que compõem regiões geolocalizadas no Hemisfério Norte, em especial países da Europa e os Estados Unidos, onde se concentram recursos tecnológicos, intelectuais, científicos e financeiros numa perspectiva de hegemonia dentro do capitalismo globalizado (Santos, 2010).

6. Cf. IBRAM (2012).

7. O presente artigo revisa informações publicadas num artigo anterior publicado em Souza (2018b), pelo Icom/Icofom sobre os parti-
A análise desses documentos digitalizados permite concluir que a mesa apresentou uma série de particularidades relacionadas à organização do evento e aos temas debatidos de forma interdisciplinar. É ponto pacífico que o documento final formulado pelos participantes - a "Carta de Santiago do Chile" - deu projeção ao termo Museu Integral ${ }^{3}$ e atribuiu outros contornos aos debates que fundamentaram posteriores teorias e terminologias museológicas. As influências das discussões latinoamericanas podem ser observadas na ênfase dada à dimensão social do museu ao longo da história e ao seu papel político nos territórios a partir das posteriores convenções realizadas pelo Conselho Internacional de Museus (ICOM). Tais ideias desdobraram-se no Movimento Internacional por uma Nova Museologia (MINoM) na década de 1980, e inspiraram diferentes museus, os quais, influenciados pelas provocações da Mesa de Santiago, procuraram atuar em consonância com a comunidade numa perspectiva social e endógena, cada vez menos centrada na "sacralização"4 dos objetos de acervo e mais focada na relação comunitária.

O evento ficou internacionalmente conhecido como Mesa Redonda de Santiago do Chile, realizado pela Divisão de Museus da Unesco em parceria com o lcom em 1972, e teve oficialmente o objetivo de pensar as especificidades de países latino-americanos dentro de uma região com experiências políticas, econômicas e culturais diversas - ainda que tivessem semelhanças estruturais em oposição aos países integrantes do "Norte global". ${ }^{5}$ Realizada entre 20 e 31 de maio de 1972, a mesa contou com a participação de especialistas latinoamericanos provenientes de Costa Rica, Argentina, Bolívia, Brasil, Chile, Colômbia, El Salvador, Equador, Guatemala, México, Panamá, Peru e Uruguai. ${ }^{\circ}$

Entre os participantes havia curadores e diretores de museus, representantes de institutos culturais, representantes do poder público ligados à área de patrimônio e museus, ${ }^{7}$ sendo a representação do Brasil protagonizada pela profissional Lygia Martins Costa, ligada ao Instituto do Patrimônio Histórico e Artístico Nacional (Iphan). Segundo Hugues de Varine (1995), especialistas que não atuavam no campo museal foram convidados a fazer uma conferência aos demais participantes para que todos juntos debatessem sobre questões consideradas cruciais à América Latina, dando prosseguimento às provocações sobre o papel social dos museus colocadas anteriormente na $9^{a}$ Conferência Geral do ICOM realizada em Grenoble, França, em 1971.

Varine destaca que a conferência de Grenoble já havia abordado a importância do entorno na vocação dos museus, além de discutir a dimensão políitica do conceito de museu, ${ }^{8}$ mas ele aponta a intervenção de Mário Vásquez como catalisadora dos ânimos sobre um novo modelo de organização para o próximo encontro que seria realizado no Chile. Dessa provocação realizada por Vásquez a 
respeito do papel do museu na sociedade, decidiu-se concentrar o tema na AméricaLatina contemporânea. Segundo Varine, a região era a dos grandes museus em México, Cuba, Brasil e Argentina que, de acordo com ele, não tinham "lições a receber" dos países que tradicionalmente protagonizavam tais conferências. ${ }^{\text {? }}$

Era a primeira vez, entre os encontros periódicos da Unesco, que os especialistas convidados eram originários exclusivamente da região que serviria de sede ao evento, considerando uma tradição de predomínio da Europa e da América do Norte nas reuniões anteriores. ${ }^{10}$ Nesse sentido, a mesa assumiu o espanhol como idioma oficial, rompendo com o que Varine apontou como uma tradição de hegemonia do inglês e do francês nas conferências até então realizadas entre a Unesco e o ICOM. ${ }^{11}$ Os participantes do evento possuíam trajetórias de engajamento político e social, dedicados à temática do desenvolvimento nos seus países a partir de diferentes perspectivas disciplinares. Tal quadro, de acordo com Varine, teria atribuído uma marca política ao encontro, dando a tônica dos debates e das resoluções propostas.

De acordo com o documento reunido pelo IBRAM, cerca de 20 especialistas trabalharam como expositores ou participantes da Mesa Redonda de Santiago, e utilizaram como base e ponto de partida os problemas comuns enfrentados na América Latina - no sentido de identificar soluções a serem propostas pelos e para os museus. Os temas de debate sugeridos e os principais debatedores, segundo o material reunido pelo IBRAM, foram:

1. "Os museus e o desenvolvimento cultural em áreas rurais e o desenvolvimento agrícola", designado a Enrique Enseñat, engenheiro da Faculdade de Agronomia da Universidade do Panamá.

2. "Os museus e o desenvolvimento científico e tecnológico", debatido por Mario Teruggi, chefe da Divisão de Mineralogia e Petrologia do Museu de la Plata, na Argentina.

3. "Os museus e os problemas sociais e culturais", discutido por Jorge Hardoy, arquiteto do Instituto Di Telia, na Argentina.

4. "Os museus e a educação permanente", provocado por César Picón Espinoza, diretor de Educação Escolar e Geral do Ministério da Educação do Peru.

Tais assuntos foram programados para serem abordados a partir de estudos de caso e de experiências pessoais e profissionais dos participantes em cada país de origem ou nos museus até então trabalhados. cipantes do evento e sobre sua data de ocorrência.

8. Op. cit.

9. Ibid., p. 143.

10. Id., 1996.

11. Sobre os deslocamentos de significados pela comunicação oral e escrita, interações linguísticas e padrões terminológicos na tentativa de conciliar discurso técnico com o discurso científico para um possível consenso vocabular em arenas supranacionais do campo museal, cf. Cerávolo, 2004. 
12. Cf. Unesco (1973).

13. Cf. IBRAM (2012).
Especialistas que não atuavam no campo museal foram convidados a fazer conferências a tais participantes para que, todos juntos, debatessem sobre questões consideradas cruciais à América Latina naquele momento e pensassem - papel dos museus com relação a essas questões. Tais pesquisadores posteriormente escreveram sobre suas conferências na revista Museum, ${ }^{12}$ publicada em 1973 com edição especialmente dedicada à América Latina e à Mesa Redonda de Santiago do Chile, com exceção de César Picón, que teve sua fala substituída na publicação pelo artigo de Juan Gómez Millas.

Interessa analisar as conferências realizadas a partir dos temas de debate em consonância com as resoluções e recomendações produzidas no evento e transcritas na publicação do IBRAM. Considerando o objetivo da mesa de estabelecer interlocuções entre profissionais que não eram do campo museal - os palestrantes - e os participantes pertencentes ao campo museal, tais documentos nos apontam a preocupação em comum com o processo de "desenvolvimento" da região a partir de diferentes pontos de vista disciplinares: a Arquitetura, a Engenharia, a Educação e a Geologia. A ideia de pensar o museu sob uma perspectiva interdisciplinar trouxe à tona, portanto, a possibilidade de refletir sobre a ordem econômico-social vigente, seja no sentido de rompê-la, seja no sentido de transformá-la.

\section{A MESA DE SANTIAGO E SEUS DEBATES SOBRE UMA AMÉRICA-LATINA EM DESENVOLVIMENTO}

Segundo o documento do IBRAM, as discussões da Mesa Redonda ocorreram na sala de reuniões do Escritório Regional da Unesco para a Educação na América Latina e no Caribe localizado na capital do Chile. De acordo com Maria Esther A. Valente (2009), o país passava por uma reorganização de seus museus por iniciativa do Departamento de Bibliotecas, Museus e Arquivos, o que pode ter se configurado como razão motivadora para que se tornasse sede do evento internacional. Para Valente, o debate interno parecia se voltar para a questão dos museus como instituições científicas e sua inserção na políitica econômica desenvolvimentista.

Não há como saber com exatidão os profissionais presentes em cada debate, nem mesmo o número de pessoas presentes no evento de maneira geral. Contudo, através do registro de deliberações ${ }^{13}$ é possível identificar apontamentos para questões comuns aos diferentes países de passado colonial, como a carência de espaços museológicos nas áreas urbanas periféricas e nas zonas rurais. Nas 
relatorias transcritas e apresentadas no documento do IBRAM, tal quadro aparece associado às assimetrias econômico-sociais globais, e estas tratadas como problemas vivenciados e reverberados nas experiências dos museus.

Sob essa perspectiva, o assunto da influência colonial sobre os processos históricos latino-americanos se fez presente nas discussões da Mesa de Santiago através do debatedor argentino Jorge Hardoy, que apontou criticamente para o processo de colonização como a referência histórica para os modelos de cidade e experiências políticas constituídas na América Latina. De acordo com a transcrição de sua fala, no seu ponto de vista, o que se constituiu na região fora um padrão de desenvolvimento urbano periférico e vertical, onde os centros de mercado concentraram a produção dos países, a população e os investimentos, se convertendo em capitais financeiras, políticas, administrativas e culturais. Na observação da Hardoy, tais regiões não coincidiam com o centro geográfico dos países, ocasionando um vazio populacional nas regiões interioranas e uma consequente desatenção do Estado. Hardoy acabou por chamar a atenção para que se discutisse a tendência à concentração das atividades econômicas em poucos centros, o que se refletia não apenas nas demandas financeiras e tecnológicas da indústria moderna, mas igualmente na concentração de equipamentos culturais nessas localidades centrais - o que incluía os museus.

Por essa perspectiva, o arquiteto argentino destacou que os projetos nacionais de investimento - relacionados a complexos industriais, construções de oleodutos, gasodutos, linhas de alta tensão, malhas rodoviárias, projetos aeroportuários, etc. - impactaram a vida urbana de forma quantitativa e qualitativa, posto que o padrão de crescimento das cidades teria a ver com a geração de emprego, a construção de moradias, escolas ou hospitais, sistemas de saneamento básico, mobilidade urbana, fornecimento de energia elétrica e cabeamento referente aos meios de comunicação. A conclusão de Hardoy pronunciada na Mesa de Santiago foi, então, que a noção de desenvolvimento empregada na América Latina dizia respeito exclusivamente ao sentido de desenvolvimento econômico - expressado por economistas em cargos-chave nos órgãos nacionais de planejamento. A consequência disso teriam sido as assimetrias sociais, constałação que se vê igualmente na fala do argentino Mário Teruggi, debatedor do tema "Os museus e o desenvolvimento científico e tecnológico", ao constatar que a "América Latina foi, como um todo, afetada pela pobreza". ${ }^{14}$

A respeito do tema desenvolvimento, interessa pensar a relação entre patrimônio e a modernização do Brasil envolvendo diferentes perspectivas intelectuais sobre o capitalismo nacional e a suposição de possibilidade de superação da condição periférica do Brasil ${ }^{15}$ perante o mundo. Nesse sentido, a discussão da
14. Ibid., p. 131.

15. Cf. Wasserman (2017). 
16. O conceito de colonialidade foi formulado por Anibal Quijano entre as décadas de 1970 e 1980 a partir de suas discussões a respeito da Modernidade, compreendida por ele como um fenômeno político, econômico e cultural de longa duração, constituído a partir da colonização da América. A colonialidade seria, portanto, a expressão desse fenômeno: um padrão mundial de poder que marca um ordenamento mundial, um projeto civilizatório universalista, onde se assume uma eurocentralidade política, econômica e cultural (Quijano, 1988).

\section{Cf. Quijano (1988).}

18. Cf. Souza (2018b)

19. No caso dos benefícios fiscais, a lei $\mathrm{n}^{\circ} 7.505$ de 1986, conhecida como Lei Sarney, estimulou esse processo de oferecimento de incentivos à iniciativa privada que disponibilizasse recursos para atividades ligadas à cultura. Entre as empresas enumeradas como "parceiras" do Iepha nesse processo, destacam-se: Metal Leve S/A Indústria e Comércio; Mannesmann S/A; Cia. Vale do Rio Doce; Alcan - Alumínio do Brasil S/A; Minerações Brasileiras Reunidas S/A; Celulose Nipo Brasileira S/A; Cia Siderúrgica Belgo Mineira; Mineração Morro Velho; Sociedade de Empreendimentos Industriais, Comerciais e Mineração S/A; Banco Desenvolvimento de Minas Gerais (BDMG); Cia Industrial de Estamparia; Cia Industrial e Mercantil de Artefatos de Ferro. Tal relação nos permite refletir sobre uma possível instrumentalização da preservação para fins de contrapartida sobre a exploração de recursos naturais pela via de incentivos fiscais. Os mesmos setores empresariais mobilizados na exploração de territórios colonialidade $^{16}$ nos oferece inspiração para pensar a mundialização dos modos de produzir, dos estilos de consumir, dos instrumentos de conhecimento e da exploração da natureza que tomam como modelo os paradigmas etnocêntricos europeus e estadunidense de uma "modernização exitosa". ${ }^{17}$ Esta, por sua vez, se torna o pano de fundo da configuração de agências e redes organizacionais dedicadas ao patrimônio, as quais passam a definir padrões gerais de práticas de preservação.

Para Paulo Peixoto e Myrian Sepúlveda (2015), a partir da década de 1970 percebe-se que as práticas de preservação em diferentes regiões adentram ao campo da circulação de valores, signos e mercadorias de apelo turístico, indicando a existência de cadeias produtivas ligadas a um "mercado de patrimonializações" que se legitimaria, entre outras coisas, por práticas compensatórias nos contextos de industrialização. No Brasil, por exemplo, observa-se o papel desempenhado pelo patrimônio na sustentação do desenvolvimento nacional a partir da criação de institutos estaduais de preservação. ${ }^{18}$ É nesse período que ocorrem intensas obras de urbanização, expansão e modernização das cidades, seguidas posteriormente do envolvimento de setores empresariais voltados à exploração de recursos naturais - mineradoras, companhias industriais, companhias de celulose, bancos de desenvolvimento, companhias de comunicação, entre outras - e o uso da preservação do patrimônio em parcerias e patrocínios, ou como contrapartida a benefícios fiscais. A título de exemplo, cabe destacar o caso de Minas Gerais, onde tais empreitadas, segundo Luciana Souza (2018b), foram narradas pelo Instituto Estadual de Patrimônio Histórico e Artístico de Minas Gerais (lepha/MG) como algo positivo, caracterizadas enquanto "mobilização à causa da preservação". ${ }^{19}$

E é desse ponto que o discurso da preservação associado ao desenvolvimento como estratégia "sustentável" nos leva a uma discussão sobre a relação entre pesquisa, ciência e desenvolvimento econômico enquanto elementos articulados pelas forças produtivas, constituintes da dialética do saber e do poder, ${ }^{20}$ onde se vê a possibilidade de instrumentalização dos conhecimentos disciplinares mobilizados para a preservação do patrimônio na manutenção ou reprodução de relações econômicas de exploração no mercado global. O patrimônio parece instrumentalizado em favor de uma continuidade de atividades voltadas à ideologia do desenvolvimento como modernização.

Sendo assim, é possível perceber o fortalecimento da articulação entre as políticas de preservação e o desenvolvimento econômico voltados ao interesse de indústrias, do comércio, e de políticas para a geração de emprego e renda e para a requalificação urbana num sentido de "progresso", enquadrada na perspectiva de uma "marcha civilizatória" preconizada por figuras como Rodrigo Melo Franco de 
Andrade à direção do Iphan. ${ }^{21} \mathrm{Na}$ adesão ao projeto de Modernidade - encarada por algumas correntes filosóficas e sociológicas como uma etapa evolutiva numa perspectiva linear de tempo 22 -, o patrimônio serviria, portanto, para legitimar o próprio avanço do capitalismo. Essa discussão toma como base os debates decoloniais de Aníbal Quijano, Ramon Grosfóguel e Walter Mignolo que enfocam a especificidade da América Latina e a colonização ibérica como fundamento para a emergência do capitalismo na sua lógica moderno-colonial. ${ }^{23}$ Aqui se configura uma divisão entre os países na posição de investimento capital e os países que ofertam mão de obra "mal protegida" ou precarizada nos direitos e garantias de dignidade humana, visados na exploração de recursos naturais e imersos nos debates sobre tal modelo de desenvolvimento como estratégia de inserção na Modernidade. ${ }^{24}$

Daqui cabe retomar parte das discussões traçadas pela Mesa de Santiago, voltadas aos problemas sociais e econômicos da América Latina, sem dissociar os museus desse processo, mas ao mesmo tempo inserindo-os na agenda de "modernização" dos países latino-americanos. Nas declarações de abertura do evento no Chile, Raymonde Frin, diretor-geral da Unesco na ocasião, discorreu sobre o encontro como uma oportunidade para buscar soluções para a integração dos museus ao desenvolvimento. De fato, nas resoluções aparecem menções sobre o papel dos museus na garantia do "desenvolvimento antropológico, socioeconômico e tecnológico" 25 ou apontamentos a respeito da necessidade de criar instituições voltadas ao desenvolvimento econômico e social.

Dos debates registrados, chama também a atenção a fala do panamenho Enrique Enseñat, responsável pelo debate "Os museus e o desenvolvimento cultural em áreas rurais e o desenvolvimento agrícola", a respeito dos esforços para o "progresso social e econômico" na América Latina, os quais, segundo ele, não estariam produzindo "resultados esperados". A fala, de sentido aparentemente dúbio, é seguida por uma menção à existência de "obstáculos" ao desenvolvimento global das comunidades rurais. Tomando como referência o morador da zona rural, Enseñat define, então, o que seria por ele considerado desenvolvimento rural: motivação, capacitação e organização da população por meio de recursos e serviços que garantissem padrões de vida elevados e efetivo exercício de cidadania. ${ }^{26} \bigcirc$ quadro de analfabetismo, precariedade no trabalho, baixos salários e insalubridade seriam causados pelo não compartilhamento de "privilégios latifundiários", os quais representariam, portanto, os tais "obstáculos" mencionados para o desenvolvimento global das comunidades.

Enseñat discorre ainda sobre a necessidade de mudança nas estruturas agrárias. Segundo ele, avanços tecnológicos, utilizados para aumentar a produção e a produtividade no campo não se voltaram à melhora dos padrões de vida e
- com desdobramentos diretos e indiretos sobre bens culturais e sobre a memória de comunidades - estiveram isentos de determinados tributos se fazendo "parceiros" do Iepha na conservação e restauração pontual de alguns bens patrimonializados. A partir desse quadro importa problematizar o desempenho dos institutos de preservação no quadro do nacional-desenvolvimentismo a partir das décadas de 1970 e 1980 (Souza, 2018a).

20. Cf. Japiassu (1977).

21. Rodrigo Melo Franco de Andrade ficou à frente da direção do Iphan entre os anos de 1937 e 1967. Em 1963, na ocasião em que recebera o título de doutor bonoris causa pela Faculdade de Arquitetura da Universidade Federal da Bahia, Rodrigo pronunciou discurso onde associava os museus e os conhecimentos disciplinares - universitários - ao desenvolvimento de "grandes nações”. Cf. Andrade (2005).

22. Cf. Dussel (2005).

23. A construção da ideia de América Latina enquanto uma unidade territorial é abordada aqui a partir dos efeitos da colonização e a construção política dos diferentes países da região em Estados-Nações. Não se evoca aqui um sentimento de territorialidade (Silva, 2005) em escala continental, mas a perspectiva de uma condição de existência geográfica, econômica, cultural e política atravessada pela experiência colonial de marca latina.

24. Cf. Souza, 2018b.

25. IBRAM (2012, p. 116). 26. Ibid. 
27. Ibid., p.122.

28. Ibid., p. 122, 123. trabalho do morador rural - que compunha parcela significativa da população latino-americana. O critério "progresso", em geral associado ao crescimento do Produto Interno Bruto, deveria tomar como referência a "justiça social" - relacionada à produção, a distribuição e o consumo de bens na sociedade. Seria necessário, portanto, "criar novas formas de propriedade, redistribuir a receita oriunda da agricultura e adotar uma nova política em relação à estrutura de governo". ${ }^{27}$ Sendo assim, a reforma agrária seria pré-requisito para melhorar a situação agrícola nos países latino-americanos. Enrique Enseñat conclui:

[...] a injustiça social é o problema mais grave e fundamental em muitos países em desenvolvimento, indicando, assim, uma distribuição desigual da riqueza, ou seja, que uma grande parcela da receita nacional é dividida entre poucos. Isso decorre da relação entre trabalho e capital, latifundiários e inquilinos, empresários e trabalhadores do campo. Devido à exploração dos trabalhadores agrícolas e à má administração e ao mau uso da terra e dos recursos naturais, além do fato de que a riqueza e os benefícios deles provenientes têm-se concentrado nas mãos de poucos, cidades têm sido condenadas a uma vida de pobreza, ignorância e insegurança. ${ }^{28}$

Ou seja, percebe-se a preocupação com a ordem econômico-social na América Latina e a mobilização de críticas voltadas ao modelo de desenvolvimento que atravessaria a realidade dos museus. Aqui importa citar o trabalho de Glauber Lima (2014) que lança um olhar crítico aos discursos e práticas museais que procuram refundar a identidade dos museus a partir da Mesa de Santiago, ressaltando que as ideias ali debatidas não estavam alheias à pauta dos movimentos sociais - principalmente entre as décadas de 1960 e 1970 -, nem tampouco às teorias desenvolvimentistas elaboradas desde a década de 1950 por organismos como a Comissão Econômica para a América Latina e Caribe das Nações Unidas (Cepal). Glauber comenta que a própria identidade institucional dos museus estaria comumente associada a propósitos desenvolvimentistas, mas que ao mesmo tempo haveria um discurso sobre um imperativo de transformação institucional para a inclusão social. De acordo com o autor, essa relação paradoxal entre "ordem" e "transformação" presente no campo museal representa sua vinculação estreita com um modelo de Modernidade marcado pela reprodução das contradições sociais em meio às relações entre mercado, Estado e sociedade.

Sobre o tema do desenvolvimento a partir do papel do Brasil no capitalismo global, diferentes correntes de pensamento se dedicaram à reflexão sobre a dialética da situação econômica brasileira entre o avanço do capitalismo e a manutenção de estruturas econômicas desiguais, excludentes e subordinadas ao Norte global. A fórmula "desenvolvimento do subdesenvolvimento" trouxe à tona debates acerca da 
"Teoria da Dependência" em variadas perspectivas sobre um "nacionaldesenvolvimentismo", reunindo autores como Celso Furtado, Caio Prado Junior, Nelson Werneck Sodré, Vania Bambirra, Theotônio do Santos, Ruy Mauro Marini, entre outros desde o princípio do século XX. ${ }^{29}$ Nessa perspectiva, o desenvolvimento e o subdesenvolvimento não estariam vinculados a fases econômicas do capitalismo, mas em relações de dependência econômica e humanitária estabelecidas entre o que chamavam de países da "periferia" e países do "centro" - os quais seriam, numa possível analogia, os países do Sul global ${ }^{30}$ e os países do Norte global.

É possível considerar, portanto, que o evento se propôs a pensar o museu a partir de marcos não apenas culturais, mas socioeconômicos que esbarravam em questões históricas, como as disputas por terra, as lutas pela redução das desigualdades e pelo reconhecimento étnico, ${ }^{31}$ o analfabetismo nas zonas rurais, a intensa migração para as zonas urbanas e a concentração de terras. Sobre este último tema, a mesaredonda assumiu um discurso favorável à reforma agrária, bandeira tão cara a movimentos sociais na América Latina - e ainda atual - e causa principal de alguns dos golpes de Estado perpetrados neste território ao longo do século XX. ${ }^{32}$

Sendo assim, é preciso não perder de vista que esse foco sobre as questões socioeconômicas regionais reafirma o peso político e simbólico da Mesa de Santiago e evidencia atravessamentos diretos ou influências indiretas das experiências de movimentos sociais de luta no campo, dos movimentos eclesiais de base, dos círculos de cultura, dos coletivos dedicados aos direitos humanos e às buscas por desaparecidos políticos, da Teologia e Filosofia da Libertação, das resistências indígenas, da Pedagogia do Oprimido, enfim, de uma série infindável de ideias e experiências históricas próprias da região que abrigava o encontro internacional e que atribuem à mesa uma singularidade política e simbólica.

\section{A POTÊNCIA DO "MUSEU INTEGRAL"}

Em relação às provocações realizadas na Mesa de Santiago pelo peruano César Picón Espinoza, designado a falar sobre Educação Permanente, o pesquisador pontuou a necessidade de rever posturas e ideias universalistas na resolução de problemas sociais. Espinoza mencionou a impossibilidade de pensar soluções e fórmulas para todas as realidades e a necessidade de considerar as especificidades de cada país: segundo ele, não seria possível criar modelos únicos para a América Latina numa espécie de "solução uniforme". Os problemas estariam enraizados em injustiças sociais, e não haveria solução possível até que tais injustiças fossem sanadas.
29. Cf. Wasserman (2017).

30. O Sul global refere-se a regiões periféricas e semiperiféricas no sistema-mundo capitalista moderno/colonial marcadas pela desigualdade nas relações sociais. Cf. Santos; Meneses (2010).

31. Este tema em específico é pouco mencionado nos documentos do IBRAM. Destaca-se apenas a fala de Mario Teruggi quando o mesmo se refere claramente ao "fraco desenvolvimento de pesquisas e tecnologias indígenas nos países latino-americanos". IBRAM (2012, p. 129).

32. René Dreifuss, Maria Helena Moreira Alves, Daniel Aarão Reis, Heloísa Starling, Rodrigo Patto Sá Motta, Carlos Fico entre outros tantos autores e autoras dedicaram suas pesquisas a pontuar e dissecar sucessivos governos latino-americanos que suprimiram movimentos sociais e atentaram contra os direitos humanos, inviabilizando projetos democráticos e sociais. Cabe destacar que tais governos atravessaram a década de 1970 , e vigoraram no período de realização da Mesa de Santiago do Chile em 1972, como a Nicarágua (onde se estabeleceu uma ditadura entre 1936 e 1980), Guatemala (de 1954 a 1996), Paraguai (1954-1989), Argentina (1962-1973), Honduras (a partir de 1956 sucessivos golpes até 1981 , e depois em 2009), Brasil (19641985), Bolívia (1964-1982), Peru (1968-1985/19922000), Uruguai (1973-1985), entre outros. Em comum, tais governos se posicionaram contrários a bandeiras ou políticas que relacionassem o "desenvolvimento territorial" a demandas por reforma agrária, ampliação de direitos sociais ou políticas públicas voltadas à di- 
minuição das desigualdades socioeconômicas.

33. IBRAM (2012, p. 123).

34. Ibid., p. 139

É nesse contexto de ideias e provocações oriundas de outros campos e disciplinas que os participantes da Mesa de Santiago chegaram à conclusão de que o museu deveria afirmar-se como "fator de mudança social". 33 Porém, segundo eles, os museus se faziam ausentes em muitos espaços ou não contemplavam temáticas a respeito dos problemas vivenciados nas zonas rurais ou sobre os processos assimétricos e excludentes da urbanização dos países latino-americanos. Por essa conclusão, os participantes tomaram como premissa a necessidade de uma mudança de postura por parte dos museus, num movimento de sensibilização interdisciplinar sobre as necessidades das comunidades e sobre os problemas específicos em nível local, regional e global.

As resoluções propostas pelos participantes da Mesa dão a entender que a mudança sugerida não se desdobraria na criação de um novo modelo de museu, mas que deveria haver uma reconfiguração dos trabalhos institucionais, e seu alcance deveria ser ampliado. Ou seja, precisaria abordar mais o tema dos problemas urbanos e rurais através de exposições, e precisariam ser criados outros museus nas zonas rurais submetidos à autoridade de museus maiores na sua respectiva região. $\bigcirc$ museu, portanto, deveria ser um meio de "difusão dos progressos", ${ }^{34}$ assim como espaço de abordagem dos problemas que assolavam especificamente a América Latina.

Neste ponto, caberia citar Tereza Scheiner (2012) em sua observação sobre - processo de organização da Mesa Redonda de Santiago do Chile e seus antecedentes históricos. Scheiner pontua que a iniciativa de realização do evento não partiu de nenhum movimento de base, mas sim da Unesco e do ICOM, cuja relação com os museus latino-americanos já havia diagnosticado demandas específicas desde o encontro de 1958 no Rio de Janeiro - sob o ponto de vista organizacional, profissional e comunicacional. Sendo assim, a autora afirma que as premissas expostas em Santiago não seriam novas, mas uma continuidade de encontros anteriores. Contudo, Scheiner não considera a contextualização políitica e social da região e a histórica ausência de políticas públicas básicas - saneamento, iluminação pública, mobilidade urbana, habitação, condições sociais de trabalho, entre outros - em áreas igualmente não contempladas por equipamentos culturais tais como os museus.

Estas questões merecem ser evidenciadas nos debates de Santiago, assim como o aparente distanciamento dos museus sobre elas, distanciamento esse diagnosticado e registrado pelos participantes do evento durante as temáticas expositivas, conforme indicam as resoluções transcritas pelo IBRAM. Não é à toa que se vê pontuada a seguinte observação nos relatórios do evento: 
Os problemas revelados pela sociedade contemporânea estão, na sua maioria, enraizados em situações de injustiça e não podem ser solucionados até que essas injustiças sejam corrigidas. Os problemas associados ao progresso das sociedades no mundo contemporâneo exigem uma visão global e uma abordagem integrada dos seus vários aspectos. Assim como a solução não se limita a uma ciência ou disciplina, a decisão sobre as melhores soluções e a forma de implementálas não pertence a um grupo social específico, mas exige a participação plena, consciente e comprometida de todos os setores da sociedade. ${ }^{35}$
35. Ibid., p. 116.

36. A referência utilizada foi o Dicionário Online Michaelis. Disponível em: $<$ https://michaelis.uol.com.br.> Consultado em: 2 fev. 2019.

37. Ibid.

A partir desse apontamento, os participantes formularam, então, a sugestão de um novo tipo de museu, onde o homem seria abordado na sua relação com o ambiente, e os problemas urbanos e rurais encarados de forma indissociada e multidisciplinar. Esse museu seria inicialmente chamado de "Museu Social", mas ao longo dos debates as expressões "Museu Integral" e "Museu Integrado" ganharam maior destaque. É interessante observar que ambas as expressões são sucessivamente utilizadas no documento como se possuíssem o mesmo significado. Contudo, no conjunto geral de discussões, resoluções e apontamentos registrados do evento, é possível traçar significativas diferenças entre ambas.

Se tomarmos as normas gramaticais do português brasileiro, Integral e Integrado constituem-se como adjetivos: expressões que determinam a condição ou a qualidade do substantivo museu. Considerando os significados destas palavras compartilhados na gramática oficial, ${ }^{36}$ Integral diz respeito a um todo, a uma composição com todos os componentes ou propriedades originais, constituindo uma relação entre variáveis. Integrado, por sua vez, seria aquilo que se integrou, foi assimilado ou se assimilou. Percebe-se, portanto, que as duas palavras evocam situações diferentes se aplicadas ao substantivo museu. É possível compreender que - "Museu Integral" poderia ser a relação entre as variáveis de um território, algo que evocasse a indissociabilidade de elementos componentes de uma realidade: a natureza e sociedade, o espaço e tempo. Se julgarmos essa interpretação possível, o conceito de "Museu Integral" já revelaria a potência de um rompimento decolonial com a lógica epistêmica - e política - fundante dos mecanismos moderno-coloniais.

Sobre esse assunto discute Edgardo Lander (2005) a partir de apontamentos acerca da constituição de saberes modernos em sucessivas cisões ontológicas, como, por exemplo, a ruptura entre corpo e mente, razão e mundo, a qual se torna base de um conhecimento descorporizado e descontextualizado, e que se pretende, portanto, dessubjetivado lou seja, toma-se como objetivo - e por isso neutro - e universal). Para Lander, esses elementos são constitutivos da modernidade cultural e se articulam com a própria organização do poder, ou seja, a conformação colonial do mundo moderno e a constituição colonial dos saberes, das linguagens, da memória, do imaginário. ${ }^{37}$ A noção de "Museu 
38. Quijano, 1988.

39. Immanuel Wallerstein (1991, 1999) criou a ideia de sistema-mundo que se constituiria como modelo ampliado de entendimento sobre sistemas históricos. O método investigativo reivindicado pelo autor para analisar a realidade consistiria em compreender em conjunto as dimensões social, política e econômica como um sistema inteiro, orgânico, de longa duração. Essa perspectiva foi estendida por alguns pesquisadores latino-americanos para sistema-mundo-moderno-colonial, considerando suas perspectivas sobre o padrão de forças estabelecidos com o fenômeno da Modernidade inaugurado pela colonização da América, tal como a colonialidade - conceito formulado pelo peruano Anibal Quijano (1988).

40. Importa destacar a posição controversa de Mário Teruggi assumida em especial na revista Museum, publicada em 1973, dedicada aos relatos dos participantes da Mesa de Santiago do Chile. Na referida publicação, o então chefe da Divisão de Mineralogia e Petrologia do Museu de la Plata pontuou a necessidade do investimento em ciência e tecnologia como estratégia de desenvolvimento da América Latina, considerando os museus de ciências como os principais divulgadores desse processo. Teruggi chega a afirmar a necessidade de se abandonar a ideia de Museu Integral, no sentido de reforçar o modelo tradicional e seu compromisso em integrar o projeto de desenvolvimento regional. Sobre essa perspectiva de Teruggi, Valente (2009) menciona alguns debates relacionados ao evento a respeito do "receio" de incorporação pelo museu de tarefas de cunho social e o risco do seu desvio de função. Segundo a autora, ha-
Integral" - no que diz respeito à sua potência - instigaria o questionamento estrutural sobre a própria organização do conhecimento na ordem modernocolonial, problematizando paradigmas etnocêntricos de organização e interpretação do mundo. Vê-se daí um novo modelo de museu que poderia colocar em cheque a própria institucionalidade: a organização do conhecimento especializado, segmentado, compartimentado, e, por isso, descontextualizado, sob um dinâmica vertical protagonizada pela figura dos "especialistas".

A expressão "Museu Integrado", por outro lado, remeteria à ideia de integração a algo já estruturado, ou assimilação a uma certa ordem existente. Se tomarmos como perspectiva a condição de colonialidade da América Latina, ${ }^{38}$ seria possível interpretar que o museu integrado não propõe uma ruptura à ordem estabelecida, mas evoca a vontade de fazer [ainda mais] parte do ambiente estruturado nas assimetrias do "sistema-mundo-moderno-colonial" 39 Não haveria, portanto, uma potência de transgressão da ordem política, econômica e cultural sobre a qual se fundamentaria a instituição museu, mas de incorporação a ela. Aqui importa lembrar a própria fala de Mario Teruggi40 na Mesa de Santiago, na qual ele ressalta que a ideia de Museu Integrado não envolveria a criação de novos museus, mas sim uma mudança no enfoque das exposições organizadas nos museus existentes. ${ }^{41}$ Mesmo nas recomendações direcionadas à Unesco, os participantes concluem a necessidade de uma nova abordagem por parte dos museus - por eles mencionado como Museu Integrado -, que deveriam "oferecer à comunidade uma visão integral do seu ambiente natural e cultural". ${ }^{42}$

Percebe-se uma possível confusão de sentidos sobre os termos Integral e Integrado: se tomarmos o conjunto de discussões realizadas no evento e transcritas pelo IBRAM, nota-se o predomínio de uma operacionalização semântica aparentemente voltada àquilo que remeteria a expressão "Museu Integrado", referindo-se ao museu como um meio de "difusão dos progressos". ${ }^{43}$ Sob essa perspectiva, tais resoluções não parecem sugerir uma nova estrutura de museu. Cabe citar novamente Glauber Lima (2014) quando o pesquisador destaca que o evento de Santiago evidencia o imperativo da ordem social e do desenvolvimento, ainda que emoldurado num discurso sobre transformação e inclusão social.

Vale a pena aqui resgatar a intenção do evento ser presidido originalmente por Paulo Freire. O educador brasileiro, natural de Pernambuco, chegou a aceitar o convite realizado por Hugue de Varine em conferir à Mesa de Santiago debates sobre adaptações possíveis de suas ideias e métodos às práticas museológicas e museográficas. ${ }^{44}$ Varine se dizia claramente influenciado ${ }^{45}$ pelo pedagogo que já na ocasião possuía obras expoentes na literatura mundial - como a Pedagogia 
do Oprimido (publicada formalmente em 1970) e Educação como Prática da Liberdade (1967), ambas produzidas durante o seu exílio no Chile.

Por sua atuação em programas de alfabetização e por sua sua vasta experiência pedagógica voltada a uma prática para a consciência das relações de força capital-trabalho na mobilização por justiça social, Paulo Freire foi preso no Brasil e posteriormente exilado na década de 1960. Por essa razão, a participação do pedagogo na mesa foi oficialmente vetada pelo delegado brasileiro da Unesco. No entanto, importa destacar que apesar do veto à presença de Paulo Freire, a Mesa de Santiago manteve o objetivo de debater e refletir sobre o papel do museu nas questões sobre as desigualdades sociais em torno das especificidades latino-americanas. É possível supor que, por essa razão, as discussões apontaram para a necessidade do museu tradicional se voltar ao tema dos problemas urbanos e rurais através de exposições.

Percebe-se que o museu evocado estaria menos ocupado à romper com estruturas políticas e epistêmicas e mais envolvido como interlocutor nos acontecimentos do presente para adentrar territórios e realizar aquilo que a $9^{a}$ Conferência Geral de Museus em Grenoble, França, afirmava na sua resolução n. 1 sobre a principal meta dos museus: "a educação e a transmissão de informações e do conhecimento por todos os meios disponíveis". ${ }^{46}$ A "transmissão" reforçaria, assim, a verticalidade das ações museológicas, a estrutura da especialidade própria do modelo tradicional ortodoxo, com pouca ou nenhuma participação ou colaboração na produção de conhecimento, discursos e atividades institucionais por parte da comunidade. O termo Museu Integrado, portanto, aparentemente se adequaria melhor a uma proposição de manutenção de uma ordem moderno-colonial vigente. ${ }^{47} \mathrm{E}$ nesses termos criariam outros museus [tradicionais] nas zonas rurais submetidos à autoridade de museus maiores na região. ${ }^{48}$

Contudo, tais elementos não excluem a potência da ideia de "Museu Integral", considerando potência como aquilo que poderia vir a ser num contexto de ideias e movimentações políticas e sociais latino-americanas. Isso significa considerar um museu que não apenas evocaria uma práxis que pusesse em cheque a fissura ontológica que separava a razão e o mundo material nas ciências modernas, ${ }^{49}$ como igualmente se veria atravessado por experiências de movimentos sociais - como movimentos indígenas, associações de moradores, círculos de cultura, comunidades eclesiais de base, brigadas camponesas, entre outras - em suas existências baseadas, inclusive, no dissenso. $\bigcirc$ "Museu Integral", no seu devir, experimentaria, portanto, a construção do museu como espaço público, ${ }^{50}$ voltado aos assuntos da comunidade - indissociada de seu território - num processo dialógico. ${ }^{51}$ via algum desconforto de que se produzisse outra Instituição que "não fosse mais um museu", posto que tomaria para si outras atribuições e incorreria num grave equívoco de se estabelecer como algo sem objetos, sem acervo.

41. IBRAM (2012, p. 133).

42. Ibid., p. 139.

43. Ibid., p. 139.

44. Varine apud Chagas (1996).

45. Hugues de Varine trabalhou com Paulo Freire entre 1971 e 1974 através do Instituto Ecumênico para o Desenvolvimento dos Povos (Inodep) que operava então em Europa, África, Ásia e América Latina, como suporte à ação comunitária nesse campo (Varine apud Chagas, 1996).

46. Scheiner (2012, p. 20).

47. Aqui cabe destacar que a origem dos museus relaciona-se ao Iluminismo no século XVIII, no bojo da formação dos Estados-nação, consolidando-se como espaços de reificação da cultura política europeia no século seguinte, e atingindo seu ápice no século $\mathrm{XX}$ (Chagas, 2005).

48. Cf. IBRAM (2012).

49. Cf. Lander (2005).

50. Cf. Ranciere (1996).

51. Cf. Freire (1970). 
52. Cf. Silva (2015).

53. Importa destacar a conjuntura de formulação desta expressão na ocasião da Conferência Geral de Museus do Icom na França, em 1971. Segundo Scheiner (2012), a partir de uma narrativa de Hugue de Varine, este teria se reunido com George Henri Rivière e o Conselheiro do Ministério do Meio Ambiente, Serge Antoine, e, motivados pelos debates, pensaram na necessidade de se criar um termo que relacionasse $m u$ seu a meio ambiente. Conforme a narrativa de Varine - descrita por Scheiner -, diferentes combinações foram experimentadas na ocasião, chegando a uma possibilidade envolvendo as palavras ecologia e $m u$ seu: Ecomuseu. Segundo ele, o termo seria usado pela primeira vez pelo $\mathrm{Mi}$ nistro Poujade pouco tempo depois, em Dijon, ainda em 1971, num discurso para 500 museólogos e museógrafos de todo o mundo (Scheiner, 2012). A partir desta narrativa, percebe-se a criação de um termo numa reduzida arena de três especialistas, num contexto geográfico europeu, mobilizados por demandas e debates que tinham mais a ver com as preocupações ambientais que assolavam países do Norte global em uma conjuntura de intensificação das industrializações nos países do Sul global. Sobre esse quadro, o próprio Varine elabora uma crítica ao termo Ecomuseu por ter se sobreposto ao termo Museu Integral ao longo da história, o que permite pensar num possível reconhecimento sobre a amplitude e potência deste último em sua perspectiva sobre o território: "A meu ver é, aliás, lamentável que o vocábulo 'ecomuseu', nascido em outras circunstâncias e com outros objetivos, tenha substituído o de $\mathrm{Mu}$ seu Integral, como que em
Cabe lembrar que a categoria território foi muitas vezes associada à preocupação com o meio ambiente. ${ }^{52}$ Aparentemente, esse foi o sentido evocado em conferências anteriores do ICOM, o que levou à formulação em 1971 da expressão "Ecomuseu". ${ }^{53}$ Este vocábulo, por sua vez, vingaria internacionalmente na Museologia no lugar de Museu Integral, como discorre posteriormente, em tom de lamento, o próprio Hugue de Varine numa constatação sobre o etnocentrismo do campo. ${ }^{54}$

Contudo, é possível interpretar que o sentido mobilizado por tal expressão aparentemente não abarcaria de maneira satisfatória a noção de território evocada no evento e trabalhada por intelectuais latino-americanos. Depreende-se dos discursos, resoluções e recomendações que o território seria um espaço múltiplo, onde o aspecto natural deveria ser compreendido de maneira relacional com o cultural, político e econômico, considerando os apontamentos de Milton Santos (2006) sobre a "geograficidade" como condição histórica nas condições de dominação - correlação de forças e poderes - e de apropriação. $\bigcirc$ território, nesse sentido seria uma totalidade - que não é unidade - dialética. ${ }^{55}$

Nesse sentido, associar a noção de integral à de território permite pensar o Museu Integral como algo que remeta a uma nova estrutura de museu a ser pensada à luz do processo dialógico proposto por Paulo Freire, de filiação à pedagogia libertadora, que tomasse como princípio a transformação da sociedade nas suas estruturas desiguais e de opressão a partir de uma práxis libertadora, numa correspondência objetiva entre o pensamento freiriano e as práticas museológicas. ${ }^{56}$ Desenvolvimento, aqui, seria concebido como o processo de transformação das assimetrias estruturais, objetivas, materiais, estabelecidas no capitalismo num contexto de mundialização dos modos de produzir, dos estilos de consumir, dos instrumentos de conhecimento e da exploração da natureza sob a bandeira do "progresso".

Os relatórios das discussões realizadas na Mesa de Santiago permitem interpretar a potência de apropriação desta ferramenta moderna - constituída na Modernidade - "museu" e a sua ressignificação como estratégia de libertação. Se tomarmos o imperativo da transformação da ordem social marcada pela desigualdade e, conforme Paulo Freire (1967, 1970), pela opressão -, o evento anuncia provocações sobre novas práticas possíveis ao afirmar, em suas resoluções, a necessidade de os museus atuarem para além das suas instalações. Hardoy, por exemplo, reforçou que a atividade museológica deveria estar integrada e comprometida com os problemas rurais e urbanos, os quais constituiriam um todo contínuo e indivisível, e materializariam os efeitos nocivos do "progresso". Por essa razão, os princípios norteadores do "Museu Integrado" apontam o que poderia vir a ser um "Museu Integral" partícipe de uma Modernidade, porém refratário às suas mazelas. 
A Mesa Redonda de Santiago do Chile não se revela um tema simples a ser explorado. A principal razão para essa constatação, é claro, se dá pela carência de documentos, posto que as fontes primárias do evento não são de fácil acesso. 0 contexto de realização da mesa igualmente complexifica sua abordagem, considerando os períodos de governos militares em países latino-americanos, golpes de Estado, supressão de direitos civis e políticos, e conformações geopolíticas na ordem da Guerra Fria que assolavam a região na década de 1970. Por fim, a trajetória histórica de determinados indivíduos que se fizeram presentes [ou ausentes de maneira forçada, como no caso de Paulo Freire] e suas experiências políticas e profissionais merece um aprofundamento maior a partir de pesquisas bibliográficas e fontes documentais. Todos esses elementos conferem ao evento um movimento de ideias absolutamente singular, permitindo a pesquisadores que se debruçam sobre o tema um variado leque de abordagens sob o ponto de vista político, econômico e cultural e a partir de perspectivas teórico-metodológicas distintas.

Como foi apontado, o contexto e as discussões realizadas no evento situaramno no debate sobre desenvolvimento socioeconômico da América Latina, contribuindo para reflexões - ainda atuais - sobre o papel dos museus nesse processo, considerando as narrativas sobre o nacional-desenvolvimentismo num quadro geopolítico onde se observavam países na posição de investimento de capital e países que ofertavam mão de obra precarizada nos direitos e garantias de dignidade humana.

Nessa seara, pensar um museu que rompesse certas barreiras discursivas ou mesmo institucionais seria inovador do ponto de vista político e simbólico. Um museu que operasse com a ideia de território numa perspectiva integradora e dialética também proporia uma nova ordem epistêmica: a do conhecimento integrado, subjetivado e em processo de desvios ou esgarçamentos possíveis com as estruturas ontológicas de saber e poder herdadas e conformadas à colonialidade. $\bigcirc$ Museu Integral, nesse sentido, se apresentaria como potência de transformação, ainda que evocado, muitas vezes, a partir do termo Museu Integrado.

Contudo, o sentido do termo Integral pode ser percebido como algo em disputa. Ao longo do evento os termos Integral e Integrado se misturaram e se confundiram nas falas, resoluções e recomendações, e muitas vezes apareceram utilizados no propósito de referendar uma agenda de inserção dos países latinoamericanos ao projeto de Modernidade pela via do desenvolvimento. Porém, algumas outras referências de ideias orbitaram nos debates da mesa e contribuíram para esgarçamentos reflexivos acerca do papel político dos museus nas realidades
54. Varine apud IBRAM (2012).

55. Cf. Silva (2015).

56. Cf. Lima (2014). 
de uma região marcada pela colonização e por relações de dependência econômica e humanitária estabelecidas, respectivamente, com países do Norte global. Desse conjunto de ideias que atravessaram a reunião, sem dúvida foram as reflexões e a práxis de Paulo Freire - em sua perspectiva de uma pedagogia para a libertação - que ainda marcam um possível devir do "Museu Integral", numa outra apropriação do museu enquanto ferramenta que, em vez de se voltar para o "progresso", serviria de instrumento de resistência à colonialidade. 


\section{REFERÊNCIAS}

LIVROS, ARTIGOS E TESES

ANDRADE, Rodrigo Melo. O patrimônio Histórico e Artístico e a Missão da Universidade. Revista do Patrimônio Histórico e Artístico Nacional. Museus: antropofagia da memória e do patrimônio, Rio de Janeiro, n. 31, p. 83-87, 2005 [1963].

CERAVOLO, Suely Moraes. Da palavra ao termo - um caminho para compreender Museologia. 2004. Tese (Doutorado em Biblioteconomia e Documentação) - Escola de Comunicação e Artes, Universidade de São Paulo, São Paulo, 2004.

CHAGAS, Mário. Respostas de Hugues de Varine às perguntas de Mário Chagas. Cadernos de Sociomuseologia, n. 5, p. 5 -11, 1996.

DUSSEL, Enrique. Europa, modernidade e eurocentrismo. In: LANDER, Edgardo (org). A colonialidade do saber: eurocentrismo e ciências sociais. Perspectivas latino americanas. Buenos Aires: Clacso, 2005. p. 24-32. Colección Sur.

FREIRE, Paulo. Educação como Prática da Liberdade. São Paulo: Paz e Terra, 2018 [1967].

FREIRE, Paulo. Pedagogia do Oprimido. São Paulo: Paz e Terra, 2018 [1970].

IBRAM, Instituto Brasileiro de Museus \& Programa Ibermuseus. Mesa redonda sobre la importancia y el desarrollo de los museos em el mundo contemporáneo: Mesa Redonda de Santiago de Chile, 1972. Nascimento Junior, José do; Trampe, Alan; Santos, Paula Assunção dos (orgs). Brasília: Ministério da Cultura, Ibermuseus, 2012.

IBRAM, Instituto Brasileiro de Museus \& Programa Ibermuseus. Revista Museum, 1973. Nascimento Junior, José do; Trampe, Alan; Santos, Paula Assunção dos (orgs). Brasília: Ministério da Cultura, Ibermuseus 2012.

JAPIASSU, Hilton. As Máscaras da Ciência. Revista Ciência da Informação, Rio de Janeiro, v. 6 , n. 1, p. 13-15, 1977.

LANDER, Edgardo. Ciências Sociais: saberes coloniais e eurocêntricos. In: LANDER, Edgardo (Org). A colonialidade do saber: eurocentrismo e ciências sociais. Perspectivas latino americanas. Buenos Aires: Clacso, 2005. p. 8-23. Colección Sur. 
LIMA, Glauber G. F. Museus, Desenvolvimento e Emancipação: O Paradoxo do Discurso Emancipatório e Desenvolvimentista na (Nova) Museologia. Museologia e Patrimônio, v. 7, p. 60-84, 2015.

POMIAN, Krzysztof. Coleção in: Memória - História. Enciclopédia Einaudi, v. 1. Lisboa: Imprensa Nacional - Casa da Moeda, 1984.

QUIJANO, Anibal. Modernidad, Identidad y utopia en América do Sul. Lima: Sociedad \& Politica, 1988.

RANCIÈRE, Jacques. O dissenso. In: NOVAES, Adauto (org.). A crise da razão. São Paulo: Companhia das Letras, 1996.

SANTOS, Boaventura. Para além do Pensamento Abissal: das linhas globais a uma ecologia de saberes. In: SANTOS, Boaventura de Sousa; MENESES, Maria Paula (Orgs.). Epistemologias do sul. São Paulo: Cortez, 2010. p. 73-119.

SANTOS, Milton. O dinheiro e o território. In: SANTOS, Milton [et al.]. Território, territórios: ensaios sobre o ordenamento territorial. $2^{\mathrm{a}}$ ed. Rio de Janeiro: DP\&A, 2006. p. 13-21.

SANTOS, Myrian Sepúlveda dos; PEIXOTO, Paulo. Patrimônios mundiais: fragmentação e mercantilização da cultura. In: PONTES, Geraldo; SANTOS, Myrian Sepúlveda dos; SOUZA, Rogério Ferreira de; PEREIRA, Victor Hugo Adler (orgs.). Cultura, memória e poder diálogos interdisciplinares. Rio de Janeiro: Eduerj, 2013. p. 233-244.

SCHEINER, T. C. M.. Repensando o Museu Integral: do conceito às práticas. Boletim do Museu Paraense Emílio Goeldi. Ciências Humanas, v. 7, p. 15-30, 2012.

SILVA, Marcos Nicolau Santos da. Território: Uma revisão teórico-conceitual. InterEspaço: Revista de Geografia e Interdisciplinaridade, v. 1, n. 1, jan./jun. 2015.

SOUZA, Luciana Christina Cruz e. Pensar os museus numa perspectiva latino-americana: a atualidade da Mesa Redonda de Santiago do Chile. In: SOARES, Bruno Brulon; BROWN, Karen; NAZOR, Olga (orgs.). Definir os museus do século XXI: experiências plurais. Paris: ICOM/ICOFOM, 2018a. p. 134-139.

SOUZA, Luciana Christina Cruz e. Patrimônio e Colonialidade - A preservação do patrimônio mineiro numa crítica decolonial. 2018. Orientador: Marcus Granato. Tese (Doutorado em Museologia e Patrimônio) - Universidade Federal do Estado do Rio de 
Janeiro; Museu de Astronomia e Ciências Afins, Programa de Pós-Graduação em Museologia e Patrimônio, Rio de Janeiro, 2018b.

UNESCO, Organização das Nações Unidas para a Educação, a Ciência e a Cultura. Levantamento trimestral de atividades e meios de pesquisa no campo da museografia. Museum. Paris: Unesco, vol. XXV, n. 3, 1973.

VALENTE, Maria Esther A. Museus de Ciência e Tecnologia no Brasil: uma 'Reunião de Família' na Mesa Redonda de Santiago do Chile em 1972. Museologia e Patrimônio, v. 2, n. 2, p. 73-86, 2009.

VARINE, Hugue. A Respeito da Mesa de Santiago. In: MATTOS, Marcelo; BRUNO, Cristina (orgs.) A Memória do Pensamento Museológico Contemporâneo: documentos e depoimentos. São Paulo: ICOM Brasil, 1995

WALLERSTEIN, Immanuel. The Modern World-System: Capitalist Agriculture and the Origins of the European World-Economy in the Sixteenth Century. Nova York: Academic Press. E-book Panitch, The Socialist Register. London: The Merlin Press, 1991 [1974].

WALLERSTEIN, Immanuel. Analise dos sistemas mundiais. In: GIDDENS, Anthony; TURNER, Jonathan (orgs.). Teoria social hoje. São Paulo: Unesp, 1999. p. 447-470.

WASSERMAN, Cláudia. A Teoria da Dependência: do nacional-desenvolvimentismo ao neoliberalismo. Rio de Janeiro: FGV, 2017.

Artigo apresentado em 24/03/2019. Aprovado em 24/09/2019.

\section{(cc) BY}

All the contents of this journal, except where otherwise noted, is licensed under a Creative Commons Attribution License 